
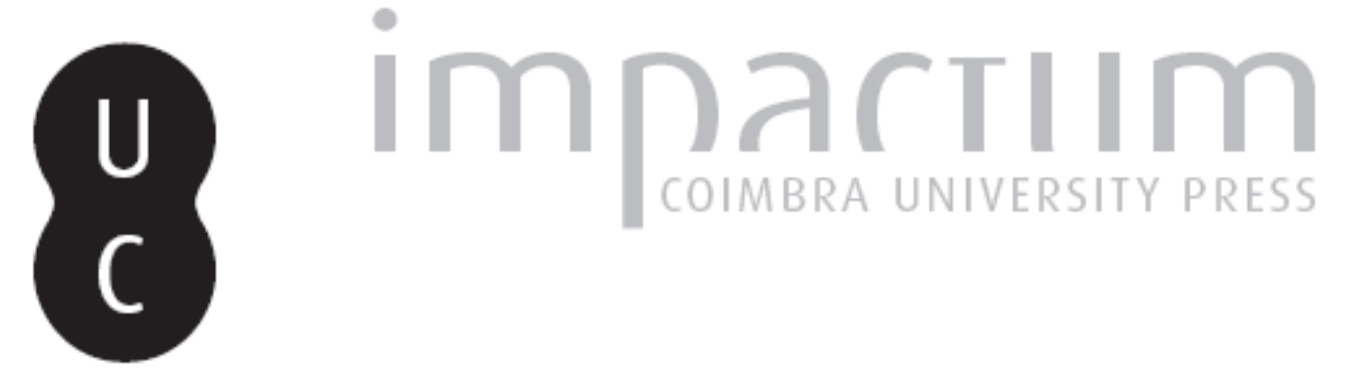

\title{
Método de avaliação de riscos para a segurança ocupacional na indústria da construção
}

Autor(es): $\quad$ Pinto, Abel; Nunes, Isabel L.; Ribeiro, Rita A.

Publicado por: Associação Portuguesa de Riscos, Prevenção e Segurança

URL

persistente:

URI:http://hdl.handle.net/10316.2/36048

DOI:

DOI:http://dx.doi.org/10.14195/1647-7723_18_5

Accessed : $\quad$ 26-Apr-2023 11:58:43

A navegação consulta e descarregamento dos títulos inseridos nas Bibliotecas Digitais UC Digitalis, UC Pombalina e UC Impactum, pressupõem a aceitação plena e sem reservas dos Termos e Condições de Uso destas Bibliotecas Digitais, disponíveis em https://digitalis.uc.pt/pt-pt/termos.

Conforme exposto nos referidos Termos e Condições de Uso, o descarregamento de títulos de acesso restrito requer uma licença válida de autorização devendo o utilizador aceder ao(s) documento(s) a partir de um endereço de IP da instituição detentora da supramencionada licença.

Ao utilizador é apenas permitido o descarregamento para uso pessoal, pelo que o emprego do(s) título(s) descarregado(s) para outro fim, designadamente comercial, carece de autorização do respetivo autor ou editor da obra.

Na medida em que todas as obras da UC Digitalis se encontram protegidas pelo Código do Direito de Autor e Direitos Conexos e demais legislação aplicável, toda a cópia, parcial ou total, deste documento, nos casos em que é legalmente admitida, deverá conter ou fazer-se acompanhar por este aviso.

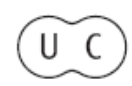




\section{territorium}

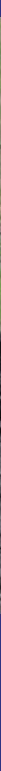

\section{Afirmar as Ciências Cindínicas}

Revista da Associação Portuguesa de Riscos, Prevenção e Segurança 
Abel Pinto

Universidade Nova Lisboa, Faculdade de Ciências e Tecnologia, Departamento de Engenharia Mecânica e Industrial, Campus de Caparica, 2829-516 Caparica, Portugal, abel.fnpinto@gmail.com

Isabel L. Nunes

Universidade Nova Lisboa, Faculdade de Ciências e Tecnologia, Departamento de Engenharia Mecânica e Industrial, Campus de Caparica, 2829-516 Caparica, Portugal, imn@fct.unl.pt

Rita A. Ribeiro

Centro de Tecnologia e Sistemas, UNINOVA, Campus de Caparica, 2829-516 Caparica, Portugal, rar@uninova.pt

RESUMO

AAnálise e Avaliação dos Riscos para a Segurança Ocupacional, na indústria da construção, é um processo complexo, que implica a consideração e análise de muitos parâmetros, técnicos, organizacionais e psicossociais difíceis de quantificar. As metodologias utilizadas são incipientes e baseadas em informação incerta, difusa, imprecisa e/ou incompleta. 0 objectivo deste trabalho é identificar os principais parâmetros e as suas relações matemáticas de forma a avaliar e hieraquizar os riscos analisados.

Palavras chave: Análise de Riscos, Avaliação de Riscos, Construção Civil, Segurança Ocupacional, Conjuntos Difusos

\section{RESUMEN}

Método de evaluación de riesgos para la seguridad en la industria de la construcción - Análisis y Evaluación de Riesgos para la seguridad, en la industria de la construcción, es un proceso complejo, lo que implica la consideración y análisis de muchos parámetros, técnicos, organizativos y psicosociales difíciles de cuantificar. las metodologías utilizadas son incipientes y basadas en información incierta, difusa, imprecisa o incompleta. El objetivo de este estudio es identificar los principales parámetros y las relaciones matemáticas para evaluar los riesgos profesionales y organizarlos en una jerarquía. Palabras clave: Análisis de riesgos, evaluación de riesgos, construcción, seguridad, Fuzzy Sets.

\section{RÉSUMÉ}

Méthode d'évaluation des risques pour la sécurité dans l'industrie de la construction - Analyse et évaluation des risques pour la sécurité, dans l'industrie de la construction, est un processus complexe, ce qui implique l'examen et l'analyse de nombreux paramètres, techniques, organisationnels et psychosociaux qui sont difficiles à quantifier. Les méthodes utilisées sont grossières et basées sur des informations incertaines, floues, imprécises et/ou incomplètes. L'objectif de cette étude est d'identifier les principaux paramètres et les relations mathématiques pour évaluer les risques et disposez-les dans une hiérarchie.

Mots-clé: Analyse des risques, Évaluation des risques, Construction, Sécurité, Fuzzy Sets.

\section{ABSTRACT}

Method of risk assessment to safety on construction industry - Analysis and Risk Assessment for Occupational Safety, on construction industry, is a complex process, which implies the consideration and analysis of many parameters, technical, organizational and psychosocial wich are difficult to quantify. The methods used are crude and based on uncertain, fuzzy, imprecise and/or incomplete information. The aim of this study is to identify the main parameters and the mathematical relationships to assess the risks and organize them in a hierarchy.

Key words: Risk Analysis, Risk Assessment, Construction, Safety, Fuzzy Sets.

* O texto deste artigo corresponde à comunicação apresentada ao II Congresso Internacional de Riscos e VI Encontro Nacional, tendo sido submetido para revisão em 28-05-2010, tendo sido aceite para publicação em 18-07-2010.

Este artigo é parte integrante da Revista Territorium, n. ${ }^{\circ} 18,2011$, ® RIscos, ISBN: 0872- 8941. 


\section{Introdução}

Devido às suas características específicas, a indústria da construção regista elevados índices de sinistralidade laboral, (TAM et al., 2004; MELIÁ et al., 2008; INE, 2008; Hyoung et al. 2009) com custos económicos elevados que afectam a produtividade do sector (SILVERSTEIN et al., 1998; Dong et al., 2007).

Vários autores (Dedobbeleer et al, 1991; Ringen et al., 1995; Gillen et al, 1997; Laitinen et al., 1999; LoOsemore et al, 2001; TAM et al., 2004) identificaram algumas das causas que afectam o nível de segurança em estaleiros de construção, das quais se destacam:

- Inadequada organização do trabalho;

- Inadequada gestão da segurança;

- Falta de formação, informação e sensibilização;

- Fraca cultura de segurança;

- Falta de coordenação e de supervisão;

- Pressões económicas e de tempo;

- Comunicação, interna e externa, ineficaz;

- Fraco envolvimento dos trabalhadores e outras partes interessadas nas questões de segurança;

- Dinâmica do acto de construir com constantes alterações e mudanças;

- Diversidade de empregadores e profissionais a laborar em simultâneo no estaleiro;

- Rotatividade laboral;

- Operação de equipamento pesado e trabalho em altura;

- Jornadas de trabalho longas e hábitos de vida pouco saudáveis;

- Cadeias de subcontratação alongadas;

- Comparativamente com outras indústrias, os trabalhadores são mais responsáveis pela organização do seu posto de trabalho e pela sua segurança;

- Fraco envolvimento da Direcção em questões de segurança e dificuldade em atribuir recursos à segurança;

- Trabalho duro e, socialmente, pouco dignificado;

- Locais de trabalho afastados dos locais de residência, com a consequente deslocação dos trabalhadores.

A Análise e Avaliação de Riscos para a Segurança Ocupacional (AARSO) é o primeiro e fundamental passo para garantir adequados níveis de segurança nos locais de trabalho. Envolve essencialmente a identificação dos perigos, caracterização e hierarquização dos riscos. É um processo complexo, que implica a caracterização de um vasto conjunto de parâmetros que são, por vezes, difíceis de quantificar.

Para se efectuar uma AARSO terá de ser determinado e avaliado um grande conjunto de variáveis de modo a conhecer as vulnerabilidades do sistema em análise. A informação a recolher e a analisar é respeitante a:

- Processos construtivos - como se faz, com que meios humanos e materiais;

- Estrutura hierárquica utilizada no processo - cadeia de comando;

- Dados históricos de ocorrências relacionadas com a segurança ocupacional - acidentes e incidentes já ocorridos no estaleiro ou em estaleiros similares;

- Objectivos a atingir - aceitação do nível de risco;

- Limites financeiros para o investimento a efectuar em função dos objectivos propostos e da viabilidade técnico-económica das soluções propostas que visam atingir os objectivos estabelecidos.

Algumas especificidades e crenças inerentes à cultura própria do sector da construção levam a que as metodologias AARSO sejam pouco usadas. AKINTOYE e MACLEOD (1997) apontam algumas das principais causas:

- A reduzida familiaridade com as metodologias AARSO disponíveis;

- O grau de sofisticação da maioria das metodologias torna difícil a sua aplicação ao sector da construção;

- A falta de tempo, de conhecimentos e de informação fiável para aplicar eficazmente as metodologias;

- As dúvidas acerca da aplicabilidade das metodologias ao sector da construção;

- A pequena dimensão da maioria das obras não permite alocar os recursos necessários à AARSO (inexistência de recursos humanos e escassez de recursos financeiros);

- Os riscos são considerados subjectivos e são avaliados com base na experiência passada (percepção);

- Os benefícios resultantes da análise de riscos não são facilmente perceptíveis;

- A AARSO não constitui, habitualmente, obrigação contratual.

Existem diversas metodologias AARSO, descritas em variadíssima literatura sobre este assunto (AvEN, 2003; Cooper et al., 2006; Hammer et al, 2001; Hollnagel, 2007; LoOSEMORE et al., 2006; RINGDAHL, 2001). Estas metodologias são baseadas em informação que, neste sector, é particularmente sujeita a incerteza, imprecisão, ambiguidade e, normalmente, incompleta. Destes factos resultam limitações apontadas por alguns autores: 
(KarWoWski et al, 1986; Cornell, 1996; WANG et al, 1997; Pender, 2001; Sil et al., 2001; Tixier et al., 2002; Faber et al, 2003; Nilsen et al, 2003; KeNTEL et al, 2004), das quais destacamos as seguintes como mais relevantes:

- Os sistemas humanos são inerentemente imprecisos;

- A dificuldade de quantificar as consequências dos perigos devido aos elevados níveis de incerteza envolvidos;

- A necessidade de efectuar estimativas, julgamentos e assumpções, tornam o processo muito dependente da capacidade do(s) analista(s), até para interpretar os resultados;

- Os empreendimentos de construção são únicos, o que reduz a relevância e a fiabilidade da utilização de técnicas estatísticas.

O objectivo principal deste trabalho é identificar os principais parâmetros que devem ser tidos em consideração num método qualitativo para AARSO, doravante denominado QRAM (Qualitative Risk Assessment Method), adequado à indústria da construção, bem como as relações matemáticas que os ligam, para avaliar e hieraquizar os riscos analisados. Para tratar a incerteza dos factores considerados no QRAM, iremos usar a teoria dos conjunto difusos (ZADEH, 1965) pois possibilita a representação, modelação e tratamento da incerteza e imprecisão intrínsecas à modelação dos riscos para a segurança laboral. Além disto permite a inclusão da criatividade humana e da intuição, que é um ingrediente essencial para uma adequada AARSO (Ru, 1996).

Pretende-se ainda que o QRAM seja centrado em dados reais, evitando as estimativas, a fim de permitir a avaliação dos riscos reais do estaleiro, com enfoque nos factores que mais concorrem para a ocorrência de acidentes ou para a sua gravidade, por forma a determinar quais as barreiras de segurança (BS) cuja implementação será mais eficiente e, por consequência com melhor relação Custo/Beneficio. Os dados podem ser obtidos por observação directa, entrevistas a trabalhadores e a encarregados e ainda por consulta e análise crítica de documentação do estaleiro (plano de segurança e de saúde, relatórios de acidentes e incidentes, actas de reuniões de obra...), entre outros.

Finalmente resta apontar que o QRAM ainda está em desenvolvimento e por esta razão são apenas descritos os conceitos básicos do método.

\section{Enquadramento Teórico}

Os acidentes de trabalho na indústria da construção ocorrem principalmente devido a: 1) falta de sensibilização ou de formação, 2) falta de supervisão,
3) falta de meios para realizar a tarefa com segurança, 4) erro de julgamento, 5) descuido, 6) apatia, 7) imprudência ou 8) condição insegura (SAWACHA et. al, 1999; Abdelhamid et al, 2000).

Modelar os factores de risco na segurança ocupacional é um fenómeno complexo (CHoudhry et al, 2008). As abordagens AARSO tradicionais são baseadas no uso de estatística e probabilidades para o tratamento dos dados. Como a informação disponível no sector da construção é imprecisa, difusa e incompleta, particularmente na fase de projecto, esta abordagem não produz resultados adequados (APELAND et al., 2002). 0 uso de técnicas probabilisticas e estatísticas podem mascarar aspectos do conhecimento incompleto e impreciso, produzindo uma falsa sensação de exatidão e precisão e conduzindo a decisões enviesadas e incorretas (ANDERSSON, 1986; FABER, 2003; NILSEN et al, 2003).

A segurança depende de factores técnicos, humanos e organizacionais. Algumas explicações apresentadas para os altos índices de acidentes na construção civil têm incluído factores organizacionais como o estilo de gestão e a política de segurança da empresa, as características pessoais como a idade, a experiência, o conhecimento e a motivação (LANDEWEER et al., 1990). O Health and Safety Executive (HSE, 2002) concluiu que o comportamento humano é o factor que contribui para cerca de $80 \%$ dos acidentes de trabalho no sector da construção. A erosão e degradação dos sistemas de gestão da segurança é, neste sector, muito provável devido a procedimentos impraticáveis, a manutenção insuficiente, a objectivos conflituosos, a falhas na comunicação ou a formação insuficiente (TRBOJEVIC, 2008).

No entanto, estes factores não se reflectem nos resultados das avaliações de riscos. Assim, os resultados das AARSO são parciais, porque só reflectem os riscos derivados de factores técnicos e podem ser enviesados devido à má "qualidade" da informação disponível. A grande limitação para a inclusão de factores organizacionais e humanos é a ausência de consenso sobre o conjunto de parâmetros relacionados com o comportamento para a segurança, a organização de segurança, a organização do trabalho, a supervisão, a liderança, os factores pessoais, a comunicação e consulta e a forma como estes afectam o desempenho da segurança, especialmente em ambientes "turbulentos" como é o caso da construção. A forma e os critérios de avaliação que se encontram descritos na literatura (Guldenmund, 2000; Mearns et al, 1999) não são facilmente praticáveis.

Pretende-se, com o QRAM, compreender os riscos existentes, nas suas várias vertentes, e hierarquizá-los, discriminando o contributo dos vários factores de risco, a fim de melhor planear e desenvolver medidas para os minimizar ou controlar. 


\section{O Processo AARSO no QRAM}

A aplicação do método QRAM será efectuada por fases, seguindo os passos do AARSO, conforme descrito por Ringdahl (2001):

1. PREPARAÇÃO: Fase que consiste em identificar o objecto de estudo que poderá envolver uma máquina, um posto de trabalho, uma frente de obra. Para esta fase é importante adquirir toda a informação relevante para a que possa ser feita a caracterização do objecto de estudo da melhor forma. Esta informação poderá ser obtida através de fotografias - do local, máquina, instalação - desenhos, reuniões de obra - onde se discutem os métodos construtivos - ou pode simplesmente recolher-se informação diversa através da observação in situ do local, posto de trabalho, execução de trabalhos semelhantes, entrevistas/questionários às pessoas envolvida no objecto de estudo. 0 objectivo é, como já referido, obter a melhor caracterização possível do objecto de estudo, sendo esta caracterização o input para a fase seguinte.

2. ESTRUTURAÇÃO (divisão em blocos): Consiste em, após identificado o sistema em estudo, dividi-lo em partes relevantes (blocos) para serem analisados à posteriori e individualmente. Após a estruturação, deverá ser analisada, de novo, a divisão proposta para se certificar de que nada foi deixado de fora. Esta estruturação, quando bem conseguida, poderá por si só deixar grandes pistas para a identificação dos perigos presentes, que será feita na fase seguinte.

3. IDENTIFICAÇÃO DE PERIGOS: Consiste na identificação de todos os objectos com potencial para causar dano presentes no sistema. Será feita por aplicação do modelo proposto neste trabalho.

4. ANÁLISE DE RISCOS: A análise de riscos, será feita por aplicação do modelo proposto neste trabalho.

5. PROPOSTA DE MEDIDAS PREVENTIVAS: As medidas preventivas propostas serão consideradas em função dos factores de risco presentes e na forma como se poderão introduzir barreiras com o intuito de os eliminar, reduzir ou isolar.

6. CONCLUSÃO: A conclusão consiste na preparação de um relatório, que congrega a análise feita e os resultados obtidos, podendo estes ser materializados através da hierarquização dos riscos presentes, medidas preventivas propostas e limites da própria análise. Poderá ser útil a elaboração de uma matriz onde é resumida toda a informação.

Após as fases de preparação e estruturação, segue-se a fase de identificação de perigos. Nesta fase pretendese identificar, de forma sistemática e criteriosa, todos os potenciais para causar dano presentes no sistema (ou bloco) em análise. Para cada forma de contacto enumerada no presente método, o analista deve procurar todas as fontes de perigo susceptíveis de provocar um acidente de trabalho por essa forma de contacto.

\section{A Análise no QRAM}

A análise com o QRAM inicia-se com a selecção de uma das forma de contacto que foram determinadas por adaptação do documento Estatisticas Europeias de Acidentes de Trabalho - Metodologia, publicado pela Comissão Europeia um 2001 e que pretende hamonizar as metodologias e os critérios que devem ser aplicados ao registo dos dados de acidentes de trabalho no espaço da União Europeia. Este documento define modalidade da lesão como "a forma do contacto que lesionou o sinistrado (revela uma acção que poderia, também, exprimir-se através de um verbo)" e, contacto como "aquilo que descreve o modo como a vítima foi lesionada (fisicamente ou por choque psicológico) pelo agente material que provocou essa mesma lesão". 0 documento enumera nove grupos, subdivididos num total de 48 formas de contacto. Desse conjunto, após entrevista não estruturada com guião, realizada a um conjunto de 10 especialistas em segurança ocupacional na construção (com 10 ou mais anos de actividade), foram seleccionadas e adaptadas as seguintes formas de contacto: Contacto (directo ou indirecto) com a electricidade, Contacto com chama viva, objecto quente ou a arder, Contacto com objecto ambiente frio ou gelado, Afogamento em matéria líquida, Soterramento sob matéria sólida, Movimento vertical, esmagamento sobre ou contra (resultado de queda), Movimento horizontal, esmagamento sobre ou contra (a vitima está em movimento), Pancada por objecto projectado, Pancada por objecto que cai, Pancada por objecto em oscilação, Pancada por objecto em rotação, movimento ou deslocação (incluíndo veículos), Colisão com objecto em movimento (incluíndo veículos) ou colisão com pessoa (a vitima está em movimento), Contacto com agente material cortante (faca, lâmina...), Contacto com agente material afiado (prego, ferramenta afiada...), Contacto com agente material duro ou áspero, Entalação ou esmagamento em, Entalação ou esmagamento sob, Entalação ou esmagamento entre, Arranque de membro, mão ou dedo, Constrangimento físico sobre o sistema músculo-esquelético. Constrangimento psíquico ou choque mental e Mordedura por, Picada por.

No QRAM utilizam-se as formas de contacto, em detrimento dos riscos, por razões de clareza. A forma de contacto é um conceito mais intuitivo para os leigos que o conceito de risco e, por tal, facilita a comunicação e o entendimento na fase de obtenção de dados empiricos, através de entrevistas com os trabalhadores e supervisores. Na prática, o que se verifica em 
documentação existente em estaleiros (Planos de Segurança e de Saúde, por exemplo), é que o termo risco é, frequentemente, usado erroneamente e, sob a denominação de "risco", o que se apresenta são formas de contacto e/ou modalidades de lesão.

\section{Tratamento da incerteza no QRAM}

No QRAM, a AARSO será baseada em dados reais. Nesta matéria (como na maioria dos problemas reais), os dados (variáveis de entrada) não são dicotómicos nem deterministicos, pelo que não podem ser tratados de forma precisa e, a descrição detalhada de um sistema real requer muito mais dados do que a capacidade de um ser humano consegue, em simultâneo, reconhecer, processar e compreender (ZimMERMAN, 1991). A teoria dos conjuntos difusos (TCD) proposta por Lotfi ZADEH (ZADEH, 1965) parecenos uma abordagem adequada para representar, de forma realista os riscos laborais e ainda apropriada para compilar os dados obtidos de uma forma uniformizada. Acresce que esta abordagem é partilhada por diversos autores que aplicam a teoria dos conjuntos difusos às áreas dos factores humanos, ergonomia e avaliação de riscos, nomeadamente: (ANDERSSON, 1986, CARR et al., 2001, Nunes, 2003, Liu et al., 2004, Mure et al., 2006, AzAdeH et al., 2008, DaGdeVIREN et al., 2008 e GuRCAnli et al., 2009).

Um modelo de análise e avaliação difuso deve incluir os processos de identificação, quantificação e combinação de variáveis para criar um modelo conceptual de decisão em ambiente difuso. 0 uso de conjuntos e operadores difusos num modelo implica (MURE et al 2009):

a) Escolha das variáveis de input e sua representação como variáveis difusas de entrada (fuzificação);

b) Definição das relações entre as as variáveis de entrada para obter as variáveis de saída (resultados) (modelo conceptual);

c) Normalização e agregação dos factores com operadores especializados.

Na próxima secção vamos apresentar os principais conceitos básicos que foram escolhidos como alicerces do modelo matemático do QRAM (i.e. modelo conceptual), como sejam os conjuntos difusos e os operadores de agregação.

\section{Teoria dos Conjuntos Difusos}

A TCD é uma teoria matemática (precisa) para lidar com a imprecisão e o raciocínio aproximado (ZADEH, 1965). Mais especificamente, a lógica difusa pode ser encarada como uma tentativa de formalização de duas notáveis capacidades humanas: 1) a capacidade de conversar, raciocinar e tomar decisões racionais em ambiente de imprecisão, incerteza, informações incompletas, informações contraditórias e parcialidade da verdade, e 2) a capacidade de tratar uma grande variedade de dados, sem efectuar medições quantitativas.

O principal conceito da TCD é o conjunto difuso. Um conjunto difuso (Zimmerman, 1993), apresenta uma fronteira com um contorno gradual, difuso, em contraste com os conjuntos clássicos, que têm fronteiras rigídas. Formalmente, seja $U$ um universo de discurso (domínio) e $u$ um elemento genérico de $U$. Um subconjunto fuzzy $A$, definido em $U$, é um conjunto de pares ordenados:

$\mathrm{A}=\{(\mathrm{u}, \mu \mathrm{A}(\mathrm{u})) \mid \mathrm{u} \in \mathrm{U}\}$

onde $\mu_{A}(u)$ é designado como o grau de pertença de $u$ em $A$. A função de pertença associa a cada elemento $u$ de $U$, um número real $\mu_{A}(u)$, no intervalo $[0,1]$, que representa a transição gradual de membro para não membro desse conjunto difuso.

Os conjuntos difusos podem ser continuos ou discretos (Zimmerman, 1993), sendo que a forma da função de pertença contém informação acerca do fenómeno em estudo, pelo que a sua escolha terá de ser adequada (descrevendo a evolução) da variável em estudo.

Por exemplo, no QRAM o conjunto difuso que modela o factor principal (gravidade dos danos no estado de saúde do acidentado) para o movimento vertical, esmagamento sobre ou contra (resultado de queda), em função da altura, será definido pelo conjunto difuso continuo apresentado na fig. 1 .

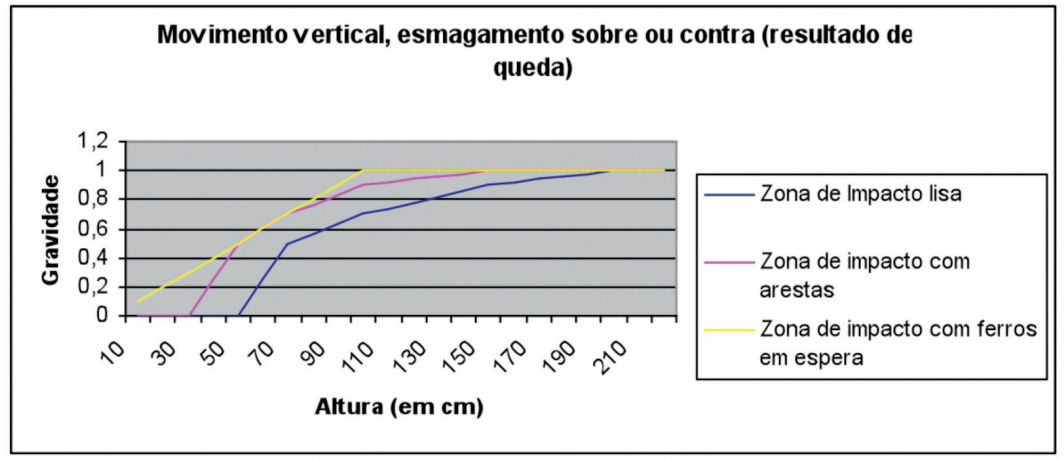

Figura 1 - Gravidade da forma de acidente "Movimento vertical, esmagamento sobre ou contra (resultado de queda)". 
Como se pode observar na Figura 1, o conjunto difuso é definido por função linear por troços, onde o domínio da variável gravidade em queda é: [0-220] $(\mathrm{cm}) \mathrm{com}$ o correspondente valor de pertença no eixo dos Y. Por exemplo o par ordenado $(100,0.70)$ refere que para uma altura de $100 \mathrm{~cm}$, estando a zona de impacto (onde o corpo de sinistrado irá embater) lisa, temos um valor de pertença no conjunto difuso "movimento vertical, esmagamento sobre ou contra (resultado de queda)" de 0.7. No caso de na zona de embate existirem objectos com arestas ou ferros em espera desprotegidos, os valores de pertença serão de 0.9 e 1 . respectivamente. O significado prático deste valores é explicado mais à frente, no sub-capítulo "Factores principais".

Outro aspecto interessante da TCD é a definição de operadores lógicos e aritméticos para proceder a operações com os conjuntos difusos. Basicamente existem quatro classes de operadores para agregar variáveis e chegar a conclusoes: a) as intersecções, b) as uniões, c) a negação e d) operadores de agregação (Zimmerman, 1993). Por exemplo se quisermos exprimir quantos homens altos "e" gordos existem um determinado conjunto, utilizamos a intersecção, se quisermos exprimir qual o grau nesse conjunto de pessoas magras, utilzamos a negação dos gordos, etc... Neste trabalho vamos utilizar essencialmente os últimos, operadores de agregação, pois o nosso objectivo é agregar as avaliações de cada um dos factores para determinar o risco global ou parcial. Especificamente a agregação entre os diversos parâmetros de risco será efectuada com recurso a operadores de média, como por exemplo a média harmónica.

Segundo Bellman e Zadeh(1970) "a tomada de decisões em contexto real ocorre em ambiente no qual as metas, os constrangimentos e as consequências de eventuais acções não são conhecidas com precisão". Este é o caso do risco no sector da construção pois é necessário agregar diversos factores imprecisos, como por exemplo o factor gravidade das consequências (ver fig. 1), para determinar o risco de acidente.

As restantes variáveis de input do modelo QRAM estão descritas adiante.

\section{Modelo Conceptual do QRAM}

O modelo proposto é baseado em pesquisa bibliográfica e conhecimento empírico da área, obtido por entrevista não estruturada com guião a um conjunto de 10 especialistas em segurança ocupacional no sector da construção (com 10 ou mais anos de actividade).

Assim, o risco é definido em função de 4 dimensões (ver expressão 1): Factores Principais $\left(F_{P}\right)$, Factores Adicionais $\left(F_{A}\right)$, Cumprimento das Prescrições de
Segurança $\left(C_{S}\right)$, e Barreiras de Segurança $\left(B_{S}\right)$. 0 nível de risco é função destas 4 dimensões. Os $F_{P}$ modelam a gravidade dos danos no estado de saúde do(s) acidentado(s), os $F_{A}$ modelam a possibilidade de ocorrência dos acidentes de trabalho e as $B_{S}$ modelam a eficácia das medidas de segurança implementadas para reduzir as consequências e/ou a possibilidade de ocorrência dos acidentes de trabalho. O cumprimento das prescrições de segurança, $C_{S}$, não respeita a uma forma de contacto em particular, sendo comum a todas as formas de contacto. É transversal a todos os perigos identificados no estaleiro, ou seja, modela o empenho de toda a cadeia hierárquica na gestão da segurança no estaleiro e o respeito pelas prescrições de segurança.

$$
R=f\left(F_{p}, F_{A}, C_{s}, B_{s}\right)
$$

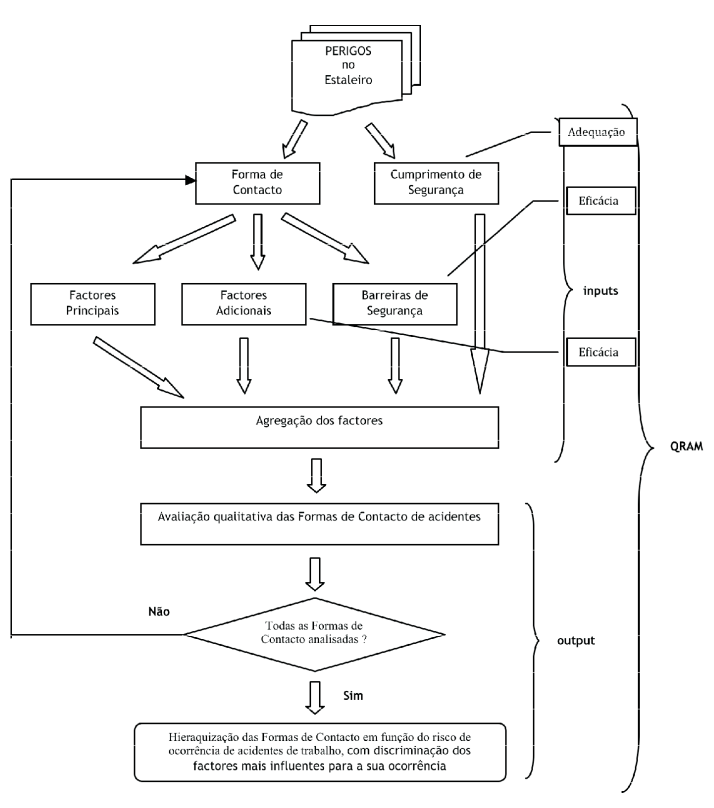

Figura 2 - Modelo conceptual do QRAM.

O modelo conceptual do QRAM, relativo ao risco (1) está descrito na fig. 2.

Para cada uma das formas de contacto enumeradas, serão analisados um conjunto de parâmetros referentes às 3 dimensões: Factores Principais, Factores Adicionais e Barreiras de Segurança.

Deve-se procurar obter informações que permitam a correcta caracterização de cada um dos parâmetros, por forma a determinar a sua magnitude. A informação pode ser obtida por várias formas: a) observação directa in-situ, b) entrevistas a trabalhadores e a encarregados e, c) consulta e análise crítica de documentação do estaleiro (plano de segurança e de saúde, relatórios de acidentes e incidentes, actas de reuniões de obra....). 
Os perigos existentes no estaleiro podem, quando um conjunto de circunstâncias (denominadas parâmetros no QRAM) se reunem num momento temporal e num ponto do espaço, originar a ocorrência de acidentes de trabalho. Para sistematizar a análise, o QRAM possui uma lista de formas de contacto para acidentes de trabalho possíveis de ocorrer em estaleiros. 0 risco associado a cada forma de contacto é modelada por parâmetros divididos em 3 dimensões: factores principais, cujos parâmetros são enumerados e modelados com conjuntos difusos contínuos, factores adicionais, cujos parâmetros são enumerados e modelados com conjuntos difusos discretos e barreiras de segurança, cujos tipos são enumerados para orientar os analistas na sua análise e cujos parâmetros são modelados com conjuntos difusos discretos.

Os parâmetros relativos ao cumprimento das prescrições de segurança, $C_{S}$ contribuem para o nível de risco na medida em que facilitam ou dificultam a implementação e manutenção da eficácia das barreiras de segurança, cujos parâmetros são enumerados e modelados com conjuntos difusos discretos. Não dependem de uma forma de contacto específica, sendo característica do estaleiro.

Os parâmetros são agregados e geram, como output, o nível de risco relativo a cada forma de contacto e enumerando os parâmetros que mais contribuiram para esse nível de risco (ver fig. 2).

Para permitir analisar e uniformizar a recolha da informação no QRAM foram definidos dois conjuntos difusos discretos. O conjunto difuso "adequação" (ver TABELA I) é utilizado para classificar os parâmetros que caracterizam os $F_{A}$ e os que caracterizam o $C_{S}$; as barreiras de segurança $B_{S}$ serão classificadas de acordo com o conjunto difuso "eficácia” (ver TABELA II).

O numero de termos foi determinado com base no trabalho de Miller que, em 1956, conjecturou que a capacidade humana tem um limite máximo para processar informação, com precisão fiável e com legitimidade, sobre elementos que interagem simultaneamente. Esse limite é de sete mais ou menos dois elementos (Saaty, Ozdemir, 2003).

Será de realçar aqui, que a classificação de "inadequado" (TABELA I) e "má" (TABELA II) usam um valor perto de zero e não zero absoluto, para evitar a sua total eliminação aquando da utilização do operador de média para agregar os factores.

Os dois conjuntos difusos foram desenvolvidos com base na experiência, e no conhecimento heuristíco acerca do tema e tendo em conta o objectivo para o qual foram definidos.
Tabela I - Conjunto difuso discreto “Adequação".

\begin{tabular}{|c|c|c|}
\hline $\begin{array}{c}\text { Termo } \\
\text { semântico }\end{array}$ & Descrição & $\begin{array}{l}\text { Grau de } \\
\text { pertença } \\
(\mu)\end{array}$ \\
\hline $\begin{array}{l}\text { Muito Bem } \\
\text { Adequado }\end{array}$ & $\begin{array}{l}\text { Cumpre todos os requisitos } \\
\text { legais, as boas práticas e outros } \\
\text { pressupostos aplicáveis, de forma } \\
\text { muito eficaz e muito consistente. }\end{array}$ & 1,0 \\
\hline $\begin{array}{l}\text { Bem } \\
\text { Adequado }\end{array}$ & $\begin{array}{l}\text { Cumpre os requisitos legais, as } \\
\text { boas práticas e outros pressupostos } \\
\text { aplicáveis, mais relevantes, de } \\
\text { forma eficaz e consistente }\end{array}$ & 0,8 \\
\hline Adequado & $\begin{array}{l}\text { Cumpre os requisitos legais, as } \\
\text { boas práticas e outros pressupostos } \\
\text { aplicáveis, mais relevantes, de } \\
\text { forma eficaz mas a consistência } \\
\text { deve ser melhorada. }\end{array}$ & 0,6 \\
\hline $\begin{array}{l}\text { Quase } \\
\text { Adequado }\end{array}$ & $\begin{array}{l}\text { Cumpre os requisitos legais, boas } \\
\text { práticas e outros pressupostos } \\
\text { aplicáveis, mas a eficácia e/ou a } \\
\text { consistência suscita dúvidas. }\end{array}$ & 0,4 \\
\hline $\begin{array}{l}\text { Pouco } \\
\text { Adequado }\end{array}$ & $\begin{array}{l}\text { Não cumpre as boas práticas ou } \\
\text { outros pressupostos aplicáveis } \\
\text { mais relevantes, de forma } \\
\text { eficaz e consistente. }\end{array}$ & 0,2 \\
\hline Inadequado & $\begin{array}{l}\text { Não cumpre um (ou mais) } \\
\text { requisitos legais aplicáveis, de } \\
\text { forma eficaz e consistente. }\end{array}$ & 0,01 \\
\hline
\end{tabular}

Tabela II - Conjunto difuso discreto "Eficácia”.

\begin{tabular}{|l|l|c|}
\hline \multicolumn{1}{|c|}{$\begin{array}{c}\text { Termo } \\
\text { semântico }\end{array}$} & $\begin{array}{c}|c| \\
\text { Erau de } \\
\text { pertença } \\
(\mu)\end{array}$ \\
\hline Excelente & $\begin{array}{l}\text { A BS estáa bem montada, } \\
\text { funciona de forma eficaz e é } \\
\text { muito fiável (tem em conta as } \\
\text { más práticas expectáveis). }\end{array}$ & 1,0 \\
\hline Muito Boa & $\begin{array}{l}\text { A BS está bem montada, } \\
\text { funciona de forma eficaz e é } \\
\text { fiável. }\end{array}$ & 0,8 \\
\hline Boa & $\begin{array}{l}\text { A BS está bem montada, } \\
\text { funciona de forma eficaz mas } \\
\text { a sua fiabilidade não está } \\
\text { devidamente assegurada. }\end{array}$ & 0,6 \\
\hline Parcial & $\begin{array}{l}\text { O funcionamento da BS não } \\
\text { é suficientemente eficaz ou } \\
\text { existem dúvidas acerca da sua } \\
\text { fiabilidade. }\end{array}$ & 0,4 \\
\hline Insuficiente & $\begin{array}{l}\text { A BS tem deficiências que a } \\
\text { tornam pouco fiável. }\end{array}$ & 0,2 \\
\hline Má & $\begin{array}{l}\text { A BS tem deficiências que a } \\
\text { tornam pouco eficaz. }\end{array}$ & 0,01 \\
\hline
\end{tabular}

Após a avaliação dos parâmetros em estudo, os valores (graus de pertença) serão agregados através de operadores de agregação de forma a obter o nível qualitativo do risco referente a cada uma das formas de contacto enumeradas, obtendo uma hierarquização das formas de contacto, em função dos riscos. Esta agregação está descrita mais à frente. 


\section{Factores Principais}

Como foi referido, os $F_{P}$ modelam a gravidade das consequências expectáveis, em termos de gravidade dos danos no estado de saúde do(s) acidentado(s), com base em parâmetros e critérios técnicos que sejam mensuráveis de forma a evitar a subjectividade da avaliação baseada na opinião dos analistas. Para tal utilizou-se, para a generalidade das formas de contacto enunciadas, o critério da energia dissipada na ocorrência dos acidentes de trabalho. Este critério é discutível por não existir uma relação causa-efeito linear e existirem factores que podem contribuir para agravar a gravidade das consequências. Por exemplo para o perigo de trabalhar em altura, a gravidade é modelada pelas variáveis: altura da queda e superfície de impacto (porque as consequências de aterrar numa superfície de areia e numa superfície com "ferros em espera", por exemplo, é substancialmente diferente.

Para sistematizar a modelação dos $F_{P}$, tendo em conta a diversidade das formas de contacto a modelar, foram considerados os seguintes intervalos de gravidade em função dos danos na saúde do acidentado:

- [0.0,05[ - nenhum dano para a saúde.

- [0.5,0.7[ - ligeiros para a saúde, recuperáveis sem tratamento hospitalar, por exemplo: lesões superficiais, dermatites, feridas e cortes menores, irritação ocular provocada por poeira.

- [0.7,0.9 - danos moderados para a saúde, recuperáveis com tratamento hospitalar, por exemplo: dilaceração, feridas abertas ou cortes profundos, queimaduras menores, entorses e distensões, concussões, fracturas menores.

- [0.9,1.0[ - danos graves para a saúde, recuperáveis com internamento hospitalar, por exemplo: queimaduras graves, lesões múltiplas, fracturas de membros inferiores.

- $\geq 1.0$ - danos extremos para a saúde, de que resulta incapacidade permanente, por exemplo: amputações; lesões oculares com perda importante da visão ou a morte.
A gravidade dos acidentes devidos a contacto (directo ou indirecto) com a electricidade, foi modelada de acordo com os critérios da norma CEI 479-1:1984, que refere o valor de $40 \mathrm{~mA}$ para o limiar de corrente para a fibrilação ventricular, para tempos de passagem superiores a $3 \mathrm{~s}$ e uma probabilidade superior a 50\% para correntes da ordem dos $90 \mathrm{~mA}$, para tempos de passagem superiores a $5 \mathrm{~s}$.

Como a fibrilação ventricular é o efeito fisiológico mais gravoso, devido à falta de resiliência do corpo humano a este efeito fisiológico, foi este que se considerou para modelar o $F_{P}$ relativo a esta forma de contacto. Tendo em atenção os valores da impedância total do corpo humano (no trajecto mão-mão ou mão-pé, para superficies de contacto de 50 a $100 \mathrm{~cm}^{2}$, em condições secas), em função da tensão, para $50 \%$ da população, que constam da tabela 1 da referida norma, modelou-se a gravidade em função da tensão, por aplicação da lei de Ohm.

A função linear por troços para o contacto (directo ou indirecto) com a electricidade, em ambiente seco, representada na Figura. 3, é:

- $[0,15 V[$ - nenhum dano para a saúde $\mu(\chi)=0,033 \chi$

- $[15,35 V[-$ danos ligeiros para a saúde $\mu(\chi)=0,01 \chi+0,35$

- [35,55V - danos moderados para a saúde $\mu(\chi)=0,01 \chi+0,35$

- $[55,120 V[$ - danos graves para a saúde $\mu(\chi)=0,015 \chi+0,82$

- $\geq 120 \mathrm{~V}$ - danos extremos para a saúde $\mu(\chi)=1$

Ainda, de acordo com a norma, a humidade (água normal) faz baixar os valores da impedância do corpo humano entre $10 \%$ e $25 \%$. Considerou-se o valor médio de $17,5 \%$.

Observando a figura 3 conclui-se que para os níveis de tensão que existem na instalação eléctrica de um estaleiro: $220 \mathrm{~V}$, em instalações monofásicas (as mais frequentes), ou $380 \mathrm{~V}$, em instalações trifásicas, o risco de fibrilação ventricular está sempre presente se a instalação não estiver protegida (em todos os seus circuitos) com protecção diferencial com sensibilidade de $30 \mathrm{~mA}$.

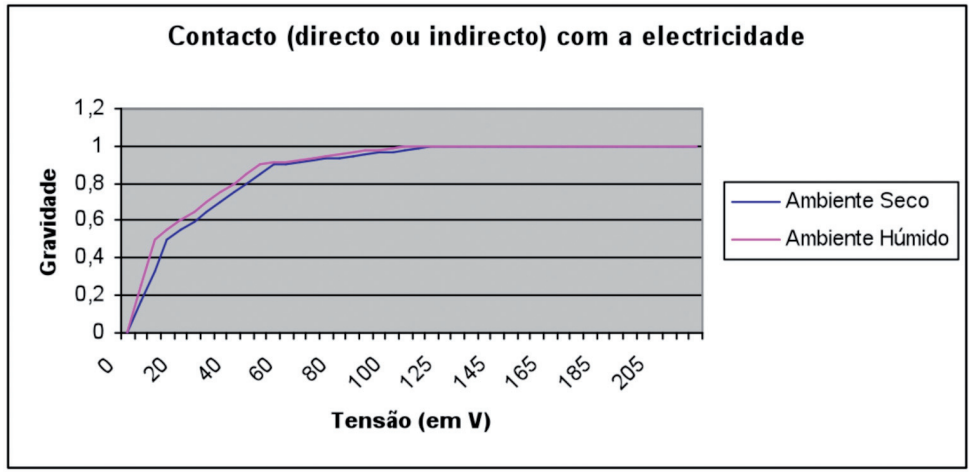

Figura 3- Gravidade da forma de acidente "Contacto (directo ou indirecto) com a electricidade". 


\section{Factores Adicionais}

Para cada forma de contacto, o número de parâmetros que caracterizam os $F_{A}$, poderá variar entre 7 e 10 (ver expressão 2) e serão agregados pelo operador média geométrica. O conjunto destes parâmetros pretende determinar a maior ou menor possibilidade de ocorrência do acidente. A sua representação depende da forma de contacto e, por exemplo, para o "movimento vertical, esmagamento sobre ou contra (resultado de queda)", serão: 1) arrumação e limpeza, 2) inclinação da superfície, 3) robustez da superfície, 4) atrito entre a superfície e o calçado, 5) nível de iluminação, 6) superfície de embate, 7) condições atmosféricas e, 8) Outros.

$$
\mathrm{F}_{A}=\mathrm{F}_{A 1} \ldots . . \mathrm{F}_{A n}
$$

A consideração do parâmetro "Outros" pretende englobar uma variedade de factores como sejam, requisitos normativos, legais ou regras da boa arte. Para cada um dos factores apontados, o analista, por observação directa, análise de registos e/ou entrevistas, deverá avaliar a sua adequação utilizando para tal o conjunto difuso “Adequação” (Tabela I).

Para o contacto (directo ou indirecto) com a electricidade, foram definidos os seguintes parâmetros:

1) levantamento das instalações eléctricas pré-existentes e respeito pelas distâncias de segurança $(0,50 \mathrm{~m}$ para canalizações eléctricas subterrâneas, $3 \mathrm{~m}$ para linhas aéreas em condutores nus de tensão até $60 \mathrm{kV}, 5 \mathrm{~m}$ para linhas aéreas de alta tensão (AT) em condutores nus de tensão superior a $60 \mathrm{kV}$ e $6 \mathrm{~m}$ para linhas aéreas muito alta tensão (MAT) em condutores nus de tensão igual ou superior a $220 \mathrm{kV}$ );

2) qualidade dos materiais e equipamento da instalação eléctrica (certificação, índice de protecção (IP) adequado ao ambiente);

3) condições da Instalação eléctrica (licenciamento, sinalização, manutenção...);

4) qualidade das ferramentas eléctricas e equipamentos de trabalho eléctricos (certificação e IP adequado ao ambiente e natureza do trabalho),

5) condições climatéricas expectáveis.

\section{Barreiras de Segurança}

Os níveis de segurança laboral podem ser aumentados, quer evitando a ocorrência de acidentes (prevenção), quer minimizando as suas consequências (protecção). Estes dois tipos de respostas, a prevenção e protecção, implicam a utilização de barreiras de segurança (Hollnagel, 2008). De acordo com Hollnagel (2006) são quatro os tipos de barreiras de segurança:
- $M$ - Barreiras materiais, impedem fisicamente o contacto do trabalhador com o perigo ou, a difusão das consequências de um evento perigoso,

- F. Barreiras funcionais, impedem a prática de acções perigosas (são exemplos destas barreiras os dispositivos de bloqueio usados em máquinas),

- $S$ - Barreiras simbólicas, necessitam ser interpretadas por um agente inteligente (sinalização, por exemplo),

- I - Barreiras imateriais, não têm presença física e dependem do conhecimento de um agente inteligente (procedimentos de trabalho, por exemplo).

Na Tabela III, apresenta-se uma síntese de de funções de BS consoante o tipo, de cordo com Hollnagel (2006).

De acordo com o mesmo autor (Hollnagel, 2008) os tipos de barreiras diferem entre si na eficácia, custo, robustez, prazo de implementação, avaliação (facilidade de) e independência do factor humano. As BS materiais e funcionais são mais eficazes em prevenir ou proteger, sendo as imateriais as menos eficazes. Por este motivo aos diferentes tipos de barreiras serão atribuídos pesos que ponderam a eficácia do seu tipo. 0 símbolo $\left({ }^{w_{i}}\right)$ na expressão 3 , indica pesos a serem atribuídos a cada tipo para transmitir por exemplo que as BS dos tipos material ( $M$ ) e funcional ( $F$ ) terão maior peso que as barreiras dos tipos simbólico $(S$ ) e imaterial ( $I$ ). É claro que uma barreira de um tipo supostamente eficaz (material, por exemplo) pode ser ineficaz devido a deficiências de projecto ou montagem.

$$
B_{S}=w_{1} M \otimes w_{2} F \otimes w_{3} S \otimes w_{4} I
$$

Para cada uma das barreiras de segurança, o analista, por observação directa, análise de registos e/ou entrevistas, deverá avaliar a sua eficácia utilizando a escala apresentada na tabela II. Os níveis de prevenção e de protecção (ou, mais usual, a combinação de ambos) corresponde à combinação da eficácia do conjunto de BS implementadas. Os vários parãmetros são agregados com o operador média geométrica.

Para o contacto (directo ou indirecto) com a electricidade, são barreiras de segurança tipo $M$, por exemplo:

a) Quadros eléctricos BT com fechadura nas porta/ tampas;

b) Dispositivos de protecção diferencial com sensibilidade e tempo de corte adequados,

c) Dispositivos de protecção contra curto-circuitos e sobrecargas com sensibilidade, tempo de corte e potência de corte adequados,

São barreiras de segurança tipo F, por exemplo:

d) Portas de celas de PTs com fechadura e encravamento,

São barreiras de segurança tipo S, por exemplo: 
Tabela III - Tipos e funções das BS.

\begin{tabular}{|c|c|c|}
\hline Tipo de BS & Função & Exemplo \\
\hline \multirow{4}{*}{ Materiais (M) } & $\begin{array}{l}\text { Conter ou proteger. Impedem a difusão e/ } \\
\text { ou a intrusão. }\end{array}$ & $\begin{array}{l}\text { Paredes, portas, edifícios, restrição de acesso físico, } \\
\text { parapeitos, vedações, filtros, contentores, tanques, válvulas, } \\
\text { rectificadores, etc }\end{array}$ \\
\hline & $\begin{array}{l}\text { Restringir ou impedir o movimento ou a } \\
\text { circulação de massas ou energia }\end{array}$ & $\begin{array}{l}\text { Cintos de segurança, arneses, vedações, gaiolas, distância } \\
\text { espacial, etc }\end{array}$ \\
\hline & Coesão, resistência & $\begin{array}{l}\text { Componentes que não quebrem facilmente (vidros de } \\
\text { segurança). }\end{array}$ \\
\hline & Separar, proteger, bloquear & Fusíveis mecânicos, purificadores, filtros, etc \\
\hline \multirow{4}{*}{ Funcionais $(\mathrm{F})$} & Evitar qualquer movimento ou acção & $\begin{array}{l}\text { Cadeados, fechaduras, interbloqueamento físico, etc... } \\
\text { Senhas, códigos de acesso, sequências de acção, pré-condições, } \\
\text { correspondência fisiológica, etc... }\end{array}$ \\
\hline & Dificultar ou impedir acções (espaço-temporal) & Distância, atrasos, sincronização, etc \\
\hline & Atenuar & Atenuadores do ruído, atenuadores de vibrações... \\
\hline & Dissipar ou extinguir energia & Air bags, pulverizadores, etc \\
\hline \multirow[b]{5}{*}{ Simbólicas (S) } & $\begin{array}{l}\text { Prevenir ou impedir acções (visual, } \\
\text { interface táctil ...) }\end{array}$ & Codificação das funções, demarcações, rótulos e avisos, etc \\
\hline & Regular acções & Instruções, procedimentos, diálogos, etc \\
\hline & $\begin{array}{l}\text { Indicar sistema de status ou condição } \\
\text { (sinais, sinais e símbolos) }\end{array}$ & Os sinais (visuais, auditivos), advertências, alarmes, etc \\
\hline & Permissão ou autorização & Autorização de trabalho, ordem de trabalho \\
\hline & $\begin{array}{l}\text { Comunicação, dependência hierárquica } \\
\text { (supervisão) }\end{array}$ & Instruções, inspecções... \\
\hline \multirow{2}{*}{ Imateriais $(\mathrm{I})$} & Respeitar conformidades & $\begin{array}{l}\text { Homolgações, normas éticas, morais, sociais e pressões de } \\
\text { grupos }\end{array}$ \\
\hline & $\begin{array}{l}\text { Prescrever: regras, leis, directrizes, } \\
\text { proibições }\end{array}$ & Regulamentos, restrições, leis, etc \\
\hline
\end{tabular}

e) Quadros eléctricos BT com porta/tampas devidamente sinalizadas;

f) Portas de celas de PTs devidamente sinalizadas;

g) Existência de procedimento para realização de trabalhos em circuitos eléctricos,

h) Existência de procedimento para inspecção de instalações/equipamentos eléctricos

E, são barreiras de segurança tipo I, por exemplo:

i) Qualidade das ferramentas do electricista (isoladas e certificadas),

j) Instalação eléctrica projectada e construida de acordo com os requisitos da Portaria n. ${ }^{\circ}$ 949-A/2006, de 11 de Setembro

k) Formação e informação dos trabalhadores.

\section{Parâmetros comportamentais}

Neste método, os parâmetros comportamentais encontram-se representados no Cumprimento das Prescrições de Segurança $\left(C_{S}\right)$ e, ao contrário dos outros factores que são especificos de um determinado perigo, é inerente ao estaleiro e, por consequência transversal a todos os perigos existentes. Não depende do perigo identificado mas "afecta" o nível do risco que advém desse perigo. Os factores referentes ao comportamento são divididos em 6 grupos (ver expressão 4).

$$
C_{S}=S c \otimes S o \otimes W o \otimes S L \otimes P \otimes C
$$

- Cultura de Segurança $\left(S_{C}\right)$ - relacionada com a existência e avaliar adequação de uma cultura de segurança ocupacional no estaleiro;

- Gestão da Segurança $\left(S_{O}\right)$ - relacionada com a existência e avaliar a eficácia do sistema de gestão da segurança ocupacional;

- Organização do Trabalho $\left(W_{O}\right)$ - relacionada com a forma como o trabalho é organizado acautela os requisitos relativos à segurança ocupacional;

- Supervisão/Liderança ( $S L$ ) - relacionada com a forma como a liderança assume as suas responsabilidades de direcção e supervisão em matéria de segurança ocupacional;

- Factores pessoais ( $P$ ) - relacionada com a forma como os factores pessoais são geridos de modo a garantir a segurança no trabalho (inclui as competências e motivação).

- Comunicação e participação $(C)$ - relacionada com a forma como os canais de comunicação estão organizados e são eficazes (incluem a aprendizagem organizacional), na troca de informações relativas à segurança ocupacional, entre os vários intervenientes no estaleiro. 
Para avaliar cada um destes factores será considerado um conjunto de 8 a 10 questões, conforme descrito nas sub-secções relativas a cada parametro.

As respostas devem reflectir o grau de adequação relativo à questão analisada. 0 analista pode obter os dados por entrevistas informais com trabalhadores e/ou supervisores, pela observação directa do comportamento dos trabalhadores e supervisores ou por avaliação de registos de segurança. Cada questão deve ser avaliada usando o conjunto difuso "Adequação" (TABELA I).

\section{Cultura de Segurança}

A cultura incorpora valores, crenças e suposições subjacentes. Uma cultura de segurança é o conjunto de pressupostos e as respectivas práticas associadas, que condicionam a percepção e a resposta ao perigo (PIDGEon et al., 2000). Segundo Cox et al. (2000) a cultura em geral, e cultura de segurança, em particular, é caracteristíca de uma organização e não é facilmente alterada. No entanto, os mesmos autores defendem que o é o clima de segurança que tem influência na ocorrência de acidentes.

A cultura de segurança e o clima de segurança são conceitos complexos. Williamson et al. (1997) descrevem clima de segurança como a ética existente numa organização ou local de trabalho e que se reflecte na percepção e opinião dos trabalhadores sobre a segurança e que permite prever o modo como os colaboradores se comportam em relação à segurança no trabalho. Cox et al. (1993) citam a declaração de GuIon (1973) "O conceito de clima organizacional é, sem dúvida importante, mas também parece ser um dos conceitos mais nebulosos do momento". Tal como a cultura, também é criado, recriado mantido e transmitido pelos membros de uma organização e influencia a forma como percepcionam os riscos, se comportam e comunicam.

Para analisar e avaliar a cultura/clima de segurança no estaleiro, foram definidas as seguintes questões:

1. Quando solicitados, os trabalhadores cooperaram na decisão e execução de medidas relacionadas com a segurança?

2. Os trabalhadores e/ou supervisores relatam todos os incidentes relacionados com a segurança?

3. Os trabalhadores (e supervisores) vêem o técnico de segurança como um valor acrescentado?

4. Existe um elevado nível de confiança entre trabalhadores, supervisores e colegas de trabalho?

5. As iniciativas relacionadas com segurança costumam ter sucesso?
6. A equipa de análise (AARSO) observa(ou) atitudes (comportamentos criticos e problemáticos) ou condições inseguras?

7. Os trabalhadores e supervisores encaram a segurança como uma prioridade quando se executam tarefas?

8. Os trabalhadores consideram o estaleiro (actual) mais seguro do que outros em que tenham trabalhado?

9. São implementadas acções correctivas sempre que a supervisão é alertada para atitudes ou condições inseguras?

10. Existe um representante da segurança escolhido pelos trabalhadores e com formação adequada?

\section{Gestão da Segurança}

Tem sido demonstrado que as políticas e programas de gestão da segurança têm relação directa com o desempenho da segurança de uma organização (DEJoy et al., 2004).

SAWACHA al. al (1999) concluem que a gestão da segurança e saúde deve ser uma parte integrante da gestão do trabalho, e quem é responsável pela coordenação das actividades deve garantir que a saúde e a segurança no trabalho são geridos de forma eficaz. Os riscos devem ser antecipados e minimizados/controlados através deBS(s) adequadas ao seu tipo e grandeza.Os equipamentos considerados necessários para garantir a segurança ocupacional devem ser incluídos nos cadernos de encargos de fornecimento de serviços.

SAWACHA et al. (1999) também concluem que a equipa de gestão da segurança no estaleiro deve identificar os principais factores que possam afectar a segurança e saúde e dos trabalhadores e informar, a priori, todos os futuros sub-empreiteiros. Um dos factores de selecção dos sub-empreiteiros deve ser a segurança, incluindo o seu registo de acidentes.

O treino e formação são factores importantes, SAWACHA et al. (1999) referem que noventa e dois por cento dos trabalhadores referem já lhes haver sido ordenado para operar máquinas sem thes haver sido dada formação adequada.

Para analisar e avaliar a gestão da segurança no estaleiro, foram definidas as seguintes questões:

1. Existe política de segurança e programas de segurança (comunicadas e implementadas) no estaleiro?

2. Os riscos para a segurança e a saúde são avaliados (incluindo os requisitos legais), controlados e devidamente comunicados aos trabalhadores?

3. Os trabalhadores sabem como trabalhar em segurança, incluíndo o uso e verificação dos EPIs necessários (é demonstrado como realizar o trabalho em segurança)? 
4. Todos os incidentes relacionados com a segurança (incluíndo os acidentes) são devidamente investigados?

5. Os registos relativos à segurança e saúde são considerados e inspeccionados no processo de selecção de sub-empreiteiros (registo de acidentes, fichas de aptidão, registos de formação...?

6. Todos os trabalhadores têm formação e treino e são sensibilizados para as prescrições de segurança?

7. Os programas de formação são regularmente revistos e actualizados?

8. Estão sempre disponíveis os equipamentos necessários para executar os trabalhos em segurança?

9. Há uma boa definição das tarefas e os procedimentos de trabalho são seguros e funcionais?

10. 0 orçamento e meios humanos afectos à segurança no estaleiro são adequados e suficientes?

\section{Organização do Trabalho}

A investigação sobre os factores que determinam a segurança em organizações industriais mostra claramente a importância dos factores de organização do trabalho e gestão dos meios de produção (FLIN, 2003). O maior obstáculo para avaliar essa dimensão é o facto de frequentemente, uma organização informal sobrepõese à organização formal do trabalho porque, embora a maior parte do trabalho nas organizações, de uma forma ou de outra, seja padronizado, os colaboradores, muitas vezes, não seguem essas normas nas suas rotinas diárias (Davoudian et al., 1994).

Prémios de produtividade levam os trabalhadores a obter maior produção em detrimento da segurança (Mullen, 2004). SAWACHA et al. (1999) e FinUCANE et al. (2000) investigaram a relação entre risco e beneficio e concluem que os trabalhadores tendem a cometer actos inseguros se, no passado, esse tipo de acto já foi de alguma forma objecto de recompensa. As organizações, ao invés de pagarem prémios de produtividade como um incentivo para para conseguir recuperar atrasos ou aumentar os lucros sem a devida preocupação com as prescrições de segurança, devem pagar prémios de segurança que combinem a produtividade e o desempenho de segurança como um único objectivo.

Shimmin et al. (1980) observam que os gestores devem perceber os esforços para assegurar condições de trabalho seguras iniciam-se na fase de concepção e preparação do projecto.

Para analisar e avaliar a organização do trabalho no estaleiro, foram definidas as seguintes questões:

1. Os objectivos operacionais nunca entram em conflito com os objectivos de segurança (por exemplo, existência incentivos financeiros para melhorar a produtividade)?

2. As etapas de construção não conflituam com particulariedades de design?

3. Existe uma boa coordenação entre as várias actividades (programação de trabalhos e critérios de priorização que evitar tarefas conflictuantes?

4. O planeamento da segurança começou na fase de projecto?

5. Os trabalhadores têm sempre tempo suficiente para executar as tarefas em segurança?

6. Há excesso de horas extraordinárias?

7. O prazo de construção é razoável?

8. As condições climatéricas expectáveis foram consideradas no planeamento e calendarização dos trabalhos?

9. Existe procedimento de autorização de trabalhos, para trabalhos de risco elevado ou para operação de equipamento pesado?

\section{Supervisão/Liderança}

Incentivos fornecidos pelos superiores (por exemplo, atenção pessoal e reconhecimento) têm mostrado consistentemente serem importantes factores de reforço no contexto organizacional, ultrapassando até os incentivos de ordem material (STAJKovic et al., 1997).

O compromisso e empenho da administração também foram identificados como factores de reforço para a obtenção de bons desempenhos de segurança (CHEYNE et al., 1998; Dedobbeleer et al., 1991; Zohar, 2002). Trabalhar em segurança implica, por vezes, trabalhar com um ritmo mais lento ou com um esforço extra (por exemplo, quando é necessário utilizar EPIs pesados e/ou desconfortáveis).

Nalgumas organizações, a segurança não é considerada em igualdade com outros aspectos do desempenho, especialmente a produtividade, pela qual os supervisores são directamente responsabilizados (FAHLBRUCH et al., 1999, citado em Zohar et al., 2003; Pate-Cornell, 1990; WRIGHT, 1986), De forma a manter bons desempenhos de segurança, mesmo sob pressão do trabalho, as administrações devem reiterar e reforçar o seu compromisso e empenho em questões de segurança e de saúde (Zohar et al., 2003).

ANDRIESSOn (1978) concluiu que os trabalhadores reagem positivamente quando o supervisor é visto como alguém que os respeita e se interessa (por eles), e cumprem as suas instruções com maior agrado e rigor. 
SaWACHA et al. (1999) concluem que as variáveis que requerem o envolvimento de gestão, tais como o relacionamento com os trabalhadores, demonstrar compromisso e empenho (vulgo dar o exemplo) e falar sobre a segurança foram considerados essenciais para um bom desempenho da segurança.

Para analisar e avaliar a adequação da supervisão/liderança no estaleiro, foram definidas as seguintes questões:

1. As relações hierárquicas estão bem definidas (especialmente em consórcios)?

2. As responsabilidades e a autoridade estão bem definidas?

3. A gestão de topo define os objectivos estratégicos de segurança para o estaleiro?

4. Existem reuniões de segurança antes de iniciar uma nova tarefa?

5. Os supervisores têm o cuidado de dar instruções de segurança e corrigir atitudes desadequadas (mostrando interesse na segurança dos trabalhadores)?

6. Os supervisores têm formação específica e utilizam métodos de liderança adequados?

7. Os supervisores demonstram preocupação quando os procedimentos não são seguidos (e explicam as consequências)?

8. O compromisso da gestão com a segurança é visível (alocando os recursos adequados e dando o exemplo no uso de EPIs, p/e)?

9. Os trabalhadores com comportamento seguro são premiados?

10. Os gestores têm conhecimento de todas as variáveis que afectam a gestão de riscos?

\section{Factores Pessoais}

As características individuais, tais como os traços de personalidade foram correlacionadas com acidentes (HANSEN, 1989). Estudos nesta área (Tomas et al., 1995), sugerem, embora não inequívocamente, que as características individuais desempenham um papel mediador na relação entre variáveis organizacionais e o desempenho de segurança porque, por exemplo, trabalhadores mais cuidadosos e conscientes conseguem superar certas fragilidades organizacionais.

O estado de saúde pode também afectar a predisposição para causar um acidente (OLIver et al., 2002). A ligação entre stress e acidentes de trabalho não é clara, embora alguns investigadores sugiram que o stress e a ansiedade desempenham um papel contributivo em incidentes e acidentes de trabalho (Cox et al., 1993 ).
Para analisar e avaliar a adequação dos factores pessoais no estaleiro, foram definidas as seguintes questões:

1. 0 estaleiro tem trabalhadores com deficiência sensorial ou aptidão mecânica inadequada?

2. O estaleiro tem trabalhadores com sensibilidade ou alergia a certas substâncias?

3. O estaleiro tem trabalhadores com asma, insuficiência respiratória ou qualquer outra doença do aparelho respiratório?

4. 0 estaleiro tem trabalhadores com falhas de memória e/ou tempos de reação lentos?

5. Os trabalhadores têm os exames médicos actualizados?

6. O estaleiro tem trabalhadores com dependências (álcool, drogas ...)?

7. 0 estaleiro tem trabalhadores com sintomas de stress ou ansiedade?

8. Os trabalhadores têm hábitos saudáveis de alimentação e higiene?

9. Os trabalhadores demonstram empenho e brio nas tarefas que executam?

\section{Comunicação/Participação}

A participação e a comunicação incentiva o conhecimento e o compromisso com as decisões relativas a práticas de trabalho seguras.

O conhecimento que os trabalhadores têm dos riscos e respectivas medidas de prevenção/protecção é fundamental para a sua motivação e colaboração no esforço de criar locais de trabalho mais seguros, sendo também um requisito legal.

Stovic (1999) conclui que a fraca eficácia dos esforços na comunicação de riscos pode ser atribuído à falta de confiança (entre trabalhadores e supervisores e/ou entre trabalhadores e técnicos de SHST). Quando os trabalhadores confiam nos supervisores e nos técnicos de SHST, as informações e avisos transmitidos são compreendidos e aceites com maior facilidade. Se essa confiança não existe, nenhuma forma ou processo de comunicação será satisfatória.

Para analisar e avaliar a adequação do processo de comunicação/participação no estaleiro, foram definidas as seguintes questões:

1. Há trabalhadores estrangeiros ou analfabetos no estaleiro?

2. Há bons canais de comunicação no estaleiro entre os diversos níveis e funções, incluindo sub-empreiteiros e trabalhadores independentes (através de reuniões periódicas, por exemplo)? 
3. As informações de segurança são dadas aos trabalhadores pela hierarquia directa?

4. Os trabalhadores são chamados a participar na identificação de perigos, avaliação de riscos e determinação das medidas de controlo de risco?

5. Os trabalhadores são chamados a participar e envolvidos na revisão dos procedimentos de segurança?

6. Existem atrasos na comunicação de informação de segurança relevante?

7. O fluxo de informação (por exemplo, procedimentos, canais verticais e horizontais, regulares e reuniões programadas) é usado como suporte à decisão (por exemplo, na definição de programa(s) de prevenção)?

Depois da identificação e classificação de todas as variáveis de input podemos então proceder à agregação dos diversos factores para obter o risco global da obra, conforme apresentado na equação (1) e representado na Figura 2 do modelo conceptual de risco.

\section{Agregação dos factores}

As variáveis de entrada descritas anteriormente serão agregadas para obter a variável de saída que corresponde ao nível de risco associado a um estaleiro, conforme apresentado na (expressão 5). Zero corresponderá a um nível de risco inexistente (corresponde à impossibilidade de ocorrência de acidente de trabalho durante a obra) e 1 corresponderá a um risco muito elevado (corresponde à forte possibilidade de ocorrência de acidente de trabalho durante a obra).

$$
R=\left[\left(1-w_{i} F_{P}\right) \square w_{i i} F_{A}\right] \oplus\left(B_{S} \otimes C_{S}\right)
$$

Os operadores de agregação vão ser escolhidos tendo em conta uma revisão bibliográfica sobre a correlação entre perigos e acidentes e por entrevista a 10 especialistas em segurança ocupacional no sector da construção, de forma a validar que os resultados (out-put do método) reflectem a realidade do estaleiro (objecto em estudo). A agregação representada na (expressão 5) vai agregar os valores de pertença $\mu(x)$ obtidos para cada uma das dimensões: factores principais, factores adicionais, barreiras de segurança e cumprimentos de segurança.

Até ao momento foram testados os operadores (Zimmerman,1993) de média aritmética (ver expressão 6), média geométrica (ver expressão 7), média harmónica (ver expressão 8) e fuzzy-OR (ver expressão 9), com grupos de 20 factores, de forma a avaliar se o resultado simula o comportamento esperado, no contexto da segurança ocupacional.

$$
M_{A}=\frac{1}{n} \sum_{i=1}^{n} \mu(x)_{i}
$$

$$
\begin{gathered}
M_{G}=\left(\prod_{i=1}^{n} \mu(x)_{i}\right)^{1 / n} \\
M_{H}=\frac{n}{\sum_{i=1}^{n} \frac{1}{\mu(x)_{i}}} \\
\text { For }=\gamma \cdot \max \left[\mu_{A}(x), \mu_{B}(x)\right]+\frac{(1-\gamma)\left[\mu_{A}(x)+\mu_{B}(x)\right]}{2}
\end{gathered}
$$

Do estudo inicial efectuado os operadores mais apropriados foram fuzzy-OR (com $\gamma=0,3$ ), média geométrica e média harmónica.

$\mathrm{Na}$ expressão $5, \chi$ representa o operador média geométrica, $\alpha$ representa o operador média harmónica, representa o operador fuzzy-OR $\operatorname{com} \gamma=0,3$.

$W_{i}$ representa os pesos (a definir) que os factores principais e adicionais têm na determinação do nível de risco.

O definição final dos operadores de agregação ainda está a ser afinada e por isso neste trabalho não discutimos mais detalhes desta importante tarefa - como combinar todos os factores associados ao risco na construção civil de forma a obter uma classificação geral de risco associado à obra.

Seguidamente apresentamos um exemplo utilizando os operadores aqui mencionados para ilustrar como todo o processo do QRAM se desenrola.

\section{Exemplo de Aplicação}

Consideremos um trabalho num andaime a três metros de altura, sobre uma zona sapatas em betão que apresentam arestas vivas. Para determinar o risco relativo à forma de contacto: "Movimento vertical, esmagamento sobre ou contra (resultado de queda)", são considerados os parâmetros que constam da (TABELA IV) mais as respectivas classificações usando os conjuntos difusos definidos nas (TABELAS I e II).

A lógica das classificações para os factores adicionais deste exemplo foi: $F_{A 1}$ (pouco limpo e arrumado) = Inadequado; $F_{A 2}$ (superfície horizontal) = Bem adequado; $F_{A 3}$ (as tábuas de pé, em madeira, apresentavam-se em bom estado de conservação) = Adequado; $F_{A 4}$ (quando seco, o material do piso proporciona bom atrito com a sola do calçado) = Adequado; $F_{A 5}$ (nível de iluminação bem adequado ao trabalho) $=$ Bem adequado; $F_{A 6}$ (tempo seco e sem vento) $=$ Muito Bem adequado e $F_{A 7}$ (o andaime cumpria todos os requisitos legais e normativos, estava bem montado e adequadamente escorado) $=$ Muito Bem adequado.

O resultado da agregação dos vários factores adicionais, conforme expressão 2, usando o operador média geométrica (expressão 7), é $F_{A}=0,57$. 
TABela IV - Dados do "Exemplo de Aplicação".

\begin{tabular}{|c|c|c|}
\hline Factores & Parâmetros & $\begin{array}{l}\text { Grau de pertença do } \\
\text { conjunto difuso }\end{array}$ \\
\hline 1. Principais & $\begin{array}{l}\text { Três metros de altura e ferros em espera na zona de } \\
\text { impacto }\end{array}$ & $\begin{array}{l}\text { 1,0 (Fig. 1, função "zona } \\
\text { de impacto com arestas") }\end{array}$ \\
\hline \multirow{7}{*}{ 2. Adicionais } & 1. Pouco limpo e arrumado & 0,01 (Tab. I - Inadequado) \\
\hline & 2. Superfície horizontal & 0,8 (Tab. I - Bem Adequado) \\
\hline & $\begin{array}{l}\text { 3. Tábuas de pé, em madeira, em bom estado de } \\
\text { conservação }\end{array}$ & 0,6 (Tab. I - Adequado) \\
\hline & $\begin{array}{l}\text { 4. Quando seco, o material do piso proporciona bom atrito } \\
\text { com a sola do calçado }\end{array}$ & 0,6 (Tab. I - Adequado) \\
\hline & 5. Nível de iluminação bem adequado ao trabalho & 0,8 (Tab. I - Bem Adequado) \\
\hline & 6. Tempo seco e sem vento & $\begin{array}{l}\text { 1,0. I - Muito Bem } \\
\text { Adequado) }\end{array}$ \\
\hline & $\begin{array}{l}\text { 7. Andaime cumpria todos os requisitos legais e normativos, } \\
\text { estava bem montado e adequadamente escorado }\end{array}$ & $\begin{array}{l}\text { 1,0 (Tab. I - Muito Bem } \\
\text { Adequado) }\end{array}$ \\
\hline \multirow{5}{*}{$\begin{array}{l}\text { 3. Barreiras de } \\
\text { Segurança }\end{array}$} & $\begin{array}{l}\text { 1. O andaime tem guarda corpos em todo o perímetro } \\
\text { exterior das plataformas de trabalho, devidamente } \\
\text { montados, em bom estado e robustos }\end{array}$ & 0,8 (Tab. II - Muito Boa) \\
\hline & 2. o lado interior dista $20 \mathrm{~cm}$ da construção & 0,8 (Tab. II - Muito Boa) \\
\hline & $\begin{array}{l}\text { 3. os acessos às plataformas de trabalho são adequados e } \\
\text { estão igualmente bem protegidos }\end{array}$ & 0,8 (Tab. II - Muito Boa) \\
\hline & $\begin{array}{l}\text { 4. A empresa implementou um procedimento para trabalhos } \\
\text { em altura, bem elaborado e redigido em linguagem } \\
\text { adequada aos seus utilizadores }\end{array}$ & 0,8 (Tab. II - Muito Boa) \\
\hline & $\begin{array}{l}\text { 5. A empresa assegura formação a todos os trabalhadores } \\
\text { que laboram em andaimes, no entanto, os registos de } \\
\text { formação não comprovam que os conhecimentos adquiridos } \\
\text { pelos formandos são devidamente avaliados e não } \\
\text { comprova a eficácia das acções de formação ministradas }\end{array}$ & 0,2 (Tab. II - Insuficiente) \\
\hline
\end{tabular}

A lógica para as barreiras de segurança foi: a) o andaime tem guarda corpos em todo o perímetro exterior das plataformas de trabalho, devidamente montados, em bom estado e robustos, $B_{S 1}=$ Muito Boa; b) o lado interior dista $20 \mathrm{~cm}$ da construção, $B_{S 2}=$ Muito Boa; c) os acessos às plataformas de trabalho são adequados e estão igualmente bem protegidos, $B_{S 3}=$ Muito Boa; d) a empresa implementou um procedimento de trabalhos em altura que contempla o trabalho em andaime, o procedimento está bem elaborado e redigido em linguagem adequada aos seus utilizadores, $B_{S 4}=$ Muito Boa; d) a empresa assegura formação a todos os trabalhadores que laboram em andaimes, no entanto, os registos de formação não comprovam que os conhecimentos adquiridos pelos formandos são devidamente avaliados e a empresa não comprova a eficácia das acções de formação ministradas, $B_{S 5}=$ Insuficiente.

Utilizando o operador média geométrica (expressão 7) para agregar estes cinco factores, conforme formulação apresentada na expressão 3 , obtemos então para as barreiras de segurança $B_{S}=0,61$

Neste exemplo, para simplificar, assume-se que o parâmetro inadequação organizacional é apenas um $C_{S}=$ Bem adequada $(0,8)$ e o seu peso é igual a 1 .

Finalmente pela expressão 5 , obtemos um risco global de queda em altura de $R=0,63$. Embora os critérios de tolerabilidade dos riscos ainda não estejam definidos, parece-nos que, neste caso o risco seria classificado de médio a elevado, sendo aconselhável implementar novas barreiras de segurança (por exemplo para "anular" ou melhorar a "adequação" do factor adicional $F_{A 1}$ ) melhorar a limpeza e arrumação das zonas de trabalho - e melhorar as BS existentes (por exemplo melhorar alguns aspectos relacionados com a formação).

\section{Conclusão}

Neste artigo apresentamos uma nova proposta de modelo de AARSO, denominado QRAM. O QRAM ainda se encontra em desenvolvimento e a ser aperfeiçoado. Uma das limitações deste método está na determinação de qual a quantidade mínima de energia que deverá ser considerada como relevante e a sua relação com a gravidade dos danos corporais. 
O QRAM é um modelo sistemático e baseado em dados reais, além de modelado com conjuntos difusos para assegurar uma maior uniformização e tratamento da incerteza inerente ao domínio. Por estas razões é mais flexível, adaptável e menos dependente das características pessoais dos analistas. No entanto, como qualquer outro processo AARSO, requer a observação e tomada de decisões que implicam julgamentos, pelo que, consideramos impossível produzir um modelo AARSO totalmente isento de toda e qualquer subjectividade e incerteza.

Os autores agradecem todas as contribuições que ajudem a desenvolver e aperfeiçoar o modelo.

\section{Agradecimentos}

Este trabalho foi financiado pela Fundação para a Ciência e Tecnologia, bolsa n SFRH / BD / 39610 / 2007.

\section{Referências bibliográficas:}

Abdelhamid, T.S. e Everett, J.G. (2000) - "Identifying root cause of construction accidents", Journal of Construction Engineering and Management, Reston, n. ${ }^{\circ} 126$ (1), p. 52-60;

Akintoye, A. S. e MacLeod, M. J. (1997) - "Risk analysis and management in construction", International Journal of Management, Hoboken, n. ${ }^{\circ}$ 15(1), p. 31-38;

Alhakami, A. S. E Slovic, P. (1994) - "A Psychological Study of the Inverse Relationship Between Perceived Risk and Perceived Benefit", Risk Analysis, New Brunswick, n. ${ }^{\circ}$ 14(6), p. 1085-1096;

Andersson, L. (1986) - "A new method based on the theory of fuzzy sets to obtaining an indication of risk", Civil Engineering and Environmental Systems, London, n. ${ }^{\circ} 3(3)$, p. 164-174;

ANDRIESSAN, J. (1978) - "Safe behavior and safe motivation", Journal of Occupational Accidents, Maryland Heights, n. ${ }^{\circ}$, p. 363-376;

Apeland, S., Aven, T., e Nilsen, T. (2002) - "Quantifying uncertainty under a predictive, epistemic approach to risk analysis", Reliability Engineering and System Safety, Maryland Heights, n. ${ }^{\circ} 75$, p. 93-102;

Aven, T. (2003) - "Foundations of Risk Analysis". John Wiley \& Sons, Chichester, 190 p.;

Azadeh, A., Fam, I. M., Khoshnoud, M. e Nikafrouz, M. (2008) - "Design and implementation of a fuzzy expert system for performance assessment of an integrated health, safety, environment (HSE) and ergonomics system: The case of a gas refinery", Information Sciences, n. ${ }^{\circ} 178$, p. 4280-4300;
Bellman, R. E. e Zadeh, L. A. (1970) “Decision-Making in a Fuzzy Environment", Management Science, n. ${ }^{\circ} 17$, p. B141-B164;

CARR, V., E TAH, J. H. M. (2001) - "A fuzzy approach to construction project risk assessment and analysis: construction project management risk systems", Advances in Engineering Software, n. ${ }^{\circ} 32$, p. 847-857;

Cheyne, A. E Al. (1998) - "Modelling safety climate in the prediction of levels of safety activity", Work and Stress, London, n. ${ }^{\circ} 12$, p. 255-271;

Choudhry, M., Fang, D. e Mohamed, S. (2007) - "The nature of safety culture: A survey of the state-of-theart”, Safety Science, Maryland Heights, n. ${ }^{\circ} 45$, p. 993-1012;

Cooper, D. F., Grey, S., Raymond, G. e Walker, P. (2006) - “Project risk management guidelines: managing risk in large projects and complex procurements", John Wiley \& Sons, Chichester, p. 384;

Cordón, O., Herrera, F. e Zwir, I. (2002) - "Linguistic Modeling by Hierarchical Systems of Linguistic Rules". IEEE TRANSACTIONS ON FUZZY SYSTEMS, n. ${ }^{\circ} 10$ (1), p. 2-20;

CoRnel, M. E. P. (1996) - "Uncertainties in risk analysis: Six levels of treatment", Reliability Engineering and System Safety, Maryland Heights, n. ${ }^{\circ}$ 54, p. 95-111;

Cox, T. E Cox, S. (1993) - "Psychosocial and organizational hazards at work: Monitoring and control", European occasional health series 5" Copenhagen, World Health Organization;

Cox, S.J. E Cheyne, A.J.T. (2000) - "Assessing safety culture in offshore environments", Safety Science, Maryland Heights, n. ${ }^{\circ}$ 34, p. 111-129;

Dagdeviren, M., e Ihsan, Y. (2008) - “Developing a fuzzy analytic hierarchy process (AHP) model for behavior-based safety management", Information Sciences, $n .^{\circ} 178$, p. 1717-1733;

Davoudian, K., Wu, J. S. e Apostolakis, G. (1994) "Incorporating organizational factors into risk assessment through the analysis of work processes", Reliability Engineering and System Safety, Maryland Heights, n. ${ }^{\circ} 45$, p. 85-105;

Dedobbeleer, N. e Beland F. (1991) - "A Safety Climate Measure for Construction Sites", Journal of Safety Research, Maryland Heights, n. ${ }^{\circ} 22$, p. 97-103;

DeJoy, D.M., Schaffer, B.S., Wilson, M.G., VandenberG, R.J. e ButTs, M.M. (2004) - "Creating safer workplaces: assessing the determinants and role of safety climate", Journal of Safety Research, Maryland Heights, n. ${ }^{\circ} 35$ (1), p. 81-90;

Dong, X., Ringen, K., Men, Y. e Fujimoto, A. (2007) - “Medical Costs and Sources of Payment for WorkRelated Injuries Among Hispanic Construction Workers", Journal of Occupational and 
Environmental Medicine, Elk Grove Village, n. ${ }^{\circ}$ 49 (12), p. 1367-1375;

Faber, M. H., e Stewart, M. G. (2003) - "Risk assessment for civil engineering facilities: critical overview and discussion", Reliability Engineering and System Safety, Maryland Heights, n. ${ }^{\circ} 80$, p. $173-184$;

Finucane, M. L., Alhakami, A., Slovic, P. e Johnson, S. (2000) - "The affect heuristic in judgments of risks and benefits", Journal of Behavioral Decision Making, Hoboken, n. ${ }^{\circ} 13$, p. 1-17;

FLIN, R. (2003) - "Danger-men at work: management influence on safety", Human Factors and Ergonomics in Manufacturing, Hoboken, n. ${ }^{\circ} 13$ (4), p. 261-268;

Gillen, M., Faucett, J. A., Beaumont, J. J. e McLoughlin, E. (1997) - "Injury severity associated with nonfatal construction falls", American Journal of Medicine, Tucson, n. ${ }^{\circ}$ 32, p. 647-655;

Guldenmund, F.W. (2000) - "The nature of safety culture: a review of theory and research", Safety Science, Maryland Heights, n. ${ }^{\circ} 34$ (1-3), p. 215-257;

Gurcanli, G. E., e Mungen, U. (2009) - “An occupational safety risk analysis method at construction sites using fuzzy sets", International Journal of Industrial Ergonomics, n. ${ }^{\circ} 39$, p. 371-387;

Hammer, W. e Price, D. (2001) - "Occupational Safety Management and Engineering", Prentice Hall Editors, New Jersey, p. 603, (5 nd edition);

HANSEN, C. P. (1989) - "A causal model of the relationship among accidents, biodata, personality and cognitive factors", Journal of Applied Psychology, Washington , n. ${ }^{\circ} 74$, p. 81-90;

Herrera, F. e Viedma, E. H. (2000) - "Linguistic decision analysis: steps for solving decision problems under linguistic information”. Fuzzy Sets and Systems, n. ${ }^{\circ} 115$, p. 67-82;

Hyoung, J., Kwon, Y., KIm. S., KIM. Y., Ju, Y. E LeE, H. (2009) - "The characteristics of fatal occupational injuries in Korea's construction industry, 19972004", Safety Science, Maryland Heights, n. ${ }^{\circ}$ 47(8), p. 1159-1162;

Hollnagel, E. (2008) - “Risk + barriers = safety?”, Safety Science, Maryland Heights, n. ${ }^{\circ} 46$, p. 221-229;

Hollnagel, E. (2006) - "Barriers and accident prevention", Ashgate Publishing, Hampshire, 227 p.;

INE (2008) - Statistical Yearbook of Portugal 2007, Instituto Nacional de Estatística (INE), Lisboa, 622 p.;

KarWowsKI, W. E MITAL, A. (1986) - "Potential Applications of Fuzzy Sets in Industrial Safety Engineering”, Fuzzy Sets and Systems, Maryland Heights, n. ${ }^{\circ}$ 19, p. 105-120;

Kentel, E., e Aral M. M. (2004) - "Probabilistic-fuzzy health risk modelling”, Stochastic Environmental
Research and Risk Assessment, Heidelberg, n. ${ }^{\circ}$ 18, p. 324-338;

Laitinen, H., Marjamaki, M., e Paivarinta, K. (1999) - “The validity of the TR safety observation method on building construction", Accident Analysis and Prevention, Maryland Heights, n. ${ }^{\circ} 31, \mathrm{p}$. 463-472;

Landeweerd, J.A., Urlings, I., De Jong, A., Nijhuis, F. E BOUteR, L. (1990) - "Risk taking tendency among construction workers", Journal of Occupational Accidents, Maryland Heights, n. ${ }^{\circ}$ 11, p. 183-196;

Liu, J., et AL. (2004) - “Fuzzy Rule-Based Evidential Reasoning Approach for Safety Analysis", International Journal of General Systems, n. ${ }^{\circ}$ 33(2-3), p. 183-204;

Loosemore, M., Raftery, J., Reilly. C. e Higgon, D. (2006) - “Risk Management in Projects", Taylor \& Francis, London, 260 p. (2nd edition);

Loosemore, M. e LeE, P. (2001) - "Communication problems with ethnic minorities in construction industry", International Journal of Project Management, Maryland Heights, n. ${ }^{\circ}$ 20, p. 517-524;

Mearns, K.J. E Flin, R. (1999) - "Assessing the state of organizational safety - culture or climate?", Current Psychology, New York, n. ${ }^{\circ} 18$ (1), p. 5-17;

Mure, S., Demichela, M. e Piccinini, N. (2006) - “Assessment of the risk of occupational accidents using a fuzzy approach", Cognition, Technology \& Work, n. ${ }^{\circ} 8$, p. 103-112;

Wang, H. e McCauley-Bell, P. (1997) - “Fuzzy regression analysis to predict risk of occupational injuries", Fuzzy Sets and Systems, Maryland Heights, n. ${ }^{\circ}$ 92(3), p. 317-340;

Williamson, A. M., Feyer, A., Cairns, D. e Biancotti, D. (1997) - "The development of a measure of safety climate: the role of safety perceptions and attitudes", Safety Science, Maryland Heights, n. ${ }^{\circ} 25$ (1-3), p. 15-27;

Melí, J. L., Mearns, K., Silva, S. e Lima, M. (2008) - "Safety climate responses and the perceived risk of accidents in the construction industry", Safety Science, Maryland Heights, n. ${ }^{\circ} 46$ (6), p. 949-958;

Mullen, J. (2004) - "Investigating factors that influence individual safety behavior at work", Journal of Safety Research, Maryland Heights, n. ${ }^{\circ} 35$ (3), p. 275-285;

Nilsen, T., E Aven, T. (2003) - "Models and model uncertainty in the context of risk analysis", Reliability Engineering and System Safety, Maryland Heights, n. ${ }^{\circ} 79$, 309-317;

Nunes, I. LoPEs. (2003) - “Modelo De Sistema Pericial Difuso Para Apoio À Análise Ergonómica De Postos De Trabalho", Dissertação de doutoramento, 
Universidade Nova de Lisboa/ Faculdade de Ciências e Tecnologia, Dep Eng Mecânica e Industrial, Almada, Portugal;

Oliver A., Cheyne A., Tomás J.M. e Cox S. (2002) - “The effects of organizational and individual factors on occupational accidents", Journal of Occupational and Organizational Psychology, Leicester, n. ${ }^{\circ} 75$ (4), p. 473-488;

Pate-Cornell, M. E. (1990) - “Organizational aspects of engineering system safety: The case of offshore platforms", Science, Washington, 250 (4985), p. 1210- 1217;

Pender, S. (2001) - "Managing incomplete knowledge: Why risk management is not sufficient", International Journal of Project Management, Maryland Heights, n. ${ }^{\circ} 19$, p. 79-87;

Pidgeon, N. e O’Leary, M. (2000) - “Man-made disasters: why technology and organizations (sometimes) fails", Safety Science, Maryland Heights, n. ${ }^{\circ}$ 34, p. 15-30;

RingdaHL, L. H. (2001) - "Safety Analysis principles and practice in occupational safety”, Taylor \& Francis, London, 294 p., (2nd edition);

Ringen, K., Englund, A., Welch, L., Weeks, J.L., Seegal, J.L. (1995) - "Why construction is different", Occupational Medicine, London, n. ${ }^{\circ} 10$ (2), 255-259;

Ru, W. G., E Eloff, J. H. P. (1996) - "Risk analysis modelling with the use of fuzzy logic", Computers \& Security, n. ${ }^{\circ} 15(3)$, p. 239-248;

SaAty, T. L. E Ozdemir, M. S. (2003) - "Why the magic number seven plus or minus two", Mathematical and Computer Modelling, n. ${ }^{\circ} 38$ (3-4), p. 233-244;

Sawacha, E., NaOUm, S. e Fong, D. (1999) - "Factors affecting safety performance on construction sites", International Journal of Project Management, Maryland Heights, n. ${ }^{\circ} 17$ (5), p. 309-315;

Shimmin, S., Corbett J. e McHugh D. (1980) - "Human Behavior: Some Aspects of Risk-taking in the Construction Industry", Institute of Civil Engineering, London, p.13-22;

Sil, H. S., Wang, J. e Ruxton, T. (2001) - “Novel risk assessment techniques for maritime safety management system", International Journal of Quality \& Reliability Management, Bingley, n. ${ }^{\circ}$ 18(8/9), p. 982-999;

Silverstein B., Welp E., Nelson N. e Kalat J. (1998) - "Claims incidence of work-related disorders of the upper extremities: Washington state, 19931999", American Journal of Public Health, Washington. N. ${ }^{\circ} 88$, p. $1827-1833$;

Stovic, P. (1999) - “Trust, Emotion, Sex, Politics, and Science: Surveying the Risk-Assessment
Battlefield”, Risk Analysis, McLean, n. ${ }^{\circ} 19$ (4), p. 689-701;

Stajkovic, A. D. e Luthans, F. (1997) - "A meta-analysis of the effects of organizational behavior modification on task performance, 1975- 95", Academy of Management Journal, Briarcliff Manor, n. ${ }^{\circ} 40$, p. 1122-1149;

Tam, C. M., Zeng, S. X. e Deng, Z. M. (2004) - “Identifying elements of poor construction safety management in China", Safety Science, Maryland Heights, n. ${ }^{\circ} 42$, p. $569-586$;

Tixier, J., Dusserre, G., Salvi, O. e Gaston, D. (2002) "Review of 62 risk analysis methodologies of industrial plants", Journal of Loss Prevention in the Process Industries, Maryland Heights, $n .^{\circ}$ 15, p. 291-303;

Tomas, J. M. e Oliver, A. (1995) - "The perceived effect of safety climate on occupational accidents", Work and Well-being: An Agenda for Europe Conference, Nottingham, 7-9 December;

TRBoJeVIC, V. M. (2008) - "Optimising hazard management by workforce engagement and supervision", Research Report RR637, Health and Safety Executive, London, 92 p.;

WRIGHT, C. (1986) - "Routine deaths: Fatal accidents in the oil industry", The Sociological Review, Hoboken, n. ${ }^{\circ} 34$, p. 265- 289;

ZADEH, L. A. (1986) - "Test-score semantics as a basis for a computational approach to the representation of meaning”. Literary \& Linguistic Computing, n. ${ }^{\circ} 1$ (1), p. 24 - 35;

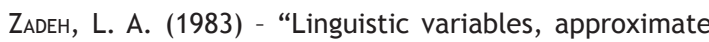
reasoning and dispositions". Informatics for Health and Social Care, n. ${ }^{\circ} 8(3)$, p. 173-186.

$Z_{A D E H}$, L. A. (1978) - “PRUF-a meaning representation language for natural languages". International Journal of Man-Machine Studies, n. ${ }^{\circ} 10, \mathrm{p}$. 395-460.

ZADEH, L. A. (1965) - "Fuzzy sets". Information and Control, n. ${ }^{\circ} 8$, p. 338-353;

Zimmerman, H. J. (1993) - "Fuzzy Set Theory and its Applications", Kluwer Academic Publishers, London, p. 399, (2nd edition)

ZohAR, D E LURIA, G. (2003) - "The use of supervisory practices as leverage to improve safety behavior: A cross-level intervention model", Journal of Safety Research, Maryland Heights, n. ${ }^{\circ} 34$, p. 567- 577;

ZoHAR, D. (2002) - "Modifying supervisory practices to improve sub-unit safety: A leadership-based intervention model", Journal of Applied Psychology, Hawthorn, n. ${ }^{\circ} 87$, p. $156-163$; 